\title{
Categorical Regression in Marketing
}

Kenneth L. Bernhardt, Georgia State University

Thomas C. Kinnear, The University of Michigan ${ }^{1}$

Market segmentation studies are currently analyzed by many sophisticated analysis techniques, among which are: regression, Multiple Classification Analysis (MCA), Au omatic Interaction Detector (AID), cluster analysis, factor analys.1:, discriminant analysis, canonical correlation and multidimensional scaling. Frank, Massey and Wind [4] present a scheme to inclicate when most of these procedures should be utilized in market segmentation analysis.

This paper presents a new multivariatc analysis technique that has great potentral for use in market s: gnentation analysis. Multivariate Nominal Scale Analysis (MNA) is a new data analysis technique developed by Frank M. Andrews ind Robert C. Messenger at the University of Michigan's Institute for Social Research [1]. Essentially, it is an extension of the Multiple Classification Analysis (MCA) program [3] that has been utlized 'n a number of marketing studies $[8,9,10]$. MCA accepts nominally scaled independent variables and assumes an intervally scaled dependent vanable. MNA accepts both nominal independent and dependent variables, in the context of an additive model.

\section{The MNA Procedure}

The primary objective of MNA is to allow the use of a regression type procedure with both nominal independent and dependent variables [1. 4-5]. A nominal criterion variable nay be exammed in the context of a set of nominal predictors with all the advantages of a multivariate regression procedure. In this context, MNA can provide useful information about: 
(a) the effect of all predictors together on the dependent variable,

(b) the effect of a specific predictor on the tependent variable while holding constant all other predictors,

(c) the marginal effect of a specific predistor over and above all other predictors,

(d) the predicted dependent variabie classification of any subject and

(e) the relationship between actual and predicted classificaton.

Related objectives include ease of input and ease of interpretation of the output. Specifically, the unique features of MNA include: (a) Dummy variables are automatically created by the MNA program thus sa $x$ ing the user considerable effort if he were to attemipt a similar procedure himself. (b) The output of MNA is easy to understand. (c) A coefficient is provided for each category of every rredictor, and the coefficients are just additions to or subtractions from the grand mean. In other dummy variable procedures, one arbitrary category of each predictor must be set to zero and other coefficients are expressed as devations from this arbitrarily omitted category. (d) MNA coefficients are more interpretable and provide more complete information. (e) MNA also hardles nonlinear relationships automatically. It is not necessary for the user to search for some best transformation with resulting difficulties in interpretation of the results.

Assurmptions MNA makes a number of what are, essentally, regressien baised assumptions including: the absence of strong, multicollinearity among the predictors, the absence of interaction (an additive model), plus the statistical assumptions that the expected value of the error term is zero, the variance of the error term is constant, error terms are uncorrelated, and that the predictors are not correlated with the error term The interaction problem may be overcome by building a pattern variable into the predictor set which would take into account both the additive and interaction effects of variables.

Limitations MNA procedes by forming dummy or 0-1 dependent variables. It us a well known property of regression that a $0-1$ dependent variable results in the variance of the error term $\mathrm{no}^{2}$ being constant. It varies with the dependent variable. Therefore, one of the statistical assumptions of the system is violated and as a result the variance of the coefficients are no longer minimum--the results are 
unbiased but inefficient which would be a major problem in statistical inference However, the second limitation of the method is that no statistical inference exists for MNA. The authors of MNA indicate that they are more interested in the sirength of relationship (as measured by the size of the coefficient) (han statistical significarice [1;71] and that it is their experience with large data sets that important relationships are almost always statistically significant [1:37]. Ancther limilation relates to the loss of netric information for uncervally scaled predictors. All predictors ale treated as nommal. The positive side of this aspect is that nonlinear relationships are found antomatically which would be hidden ty a metric procedure.

Mathematical Overview The MNA prucedure is a relatively now one, so most readers are likely to be unfarniliar with it. Therefore, the next section of this article presents a mathematical overview of how MNA works (see [1:21-30] for details).

MNA is based on the repeated application of least squares dummy variable regression [11]. Specifically, the set of onginal predictor variables $\left(X_{1}, X_{2}, \ldots, X_{p}\right)$ s tansformed into a set of dummy predictor variables $\left(x_{1}, x_{2}, \ldots, \lambda c_{1} \ldots x_{r}\right)$ by treatıng every nonempty code of eack predictor as a nu'w dummy variable and by assigning a value of 1 when the code appears and 0 when it does not appear.

The resulting data set of dummy predictors has one linear $\mathrm{d}$ pendency for each set of dummy predictiors associated with an original predictor. These yield a singular matrix which prevents proper least squares estimation from being carriad out. Therefore, the lyear dependencies must be eliminated by omitt nig one dummy predictor from each set. This procedure yields a set of $r=c-p$ independent prediators, where $\mathrm{c}=$ the total number of categories in the dependent variables and $p=$ the number of predictors.

This procedure is completely analogrus to multistate dummy in regular regression where an attribute has more than two levels. For example, the four category prediction variable geographic region would have the following codes available.

Northeast

100

Midwest

010

South

001

West

000

We note the removal of the linear dependincy with the assignment of all zeros to the West dummy variable.

The dependent variable is also duranyyized to form a set of $\mathbf{G}$ durnmy dependent variables where $G$ is tat number of nonompty 
dependent variable codes. Then, the set of $r$ predictors is applied successively to the complete set of $\mathrm{G}$ dummy dependent variables, using the criterion of minimizing the error sum of squares, which forms the least squares criterion, given by:

$$
\mathbf{E S S}_{l}=\Sigma_{\mathbf{w}_{k}} \quad\left(y_{k l}-y_{l l}\right)^{2} \quad(l=1,2, \ldots \mathrm{G})
$$

where

ESS $_{l}=$ error sums of squares for the lth dummy dependent variable,

$w_{\mathbf{k}}=$ nndıvidual $\mathbf{k}$ s weight,

$y_{k l}=$ individual k's score or the lth dummy dependent variable,

$\hat{y}_{k l}=$ individual $k$ 's predicted score for the lth dummy dependent variable

and where

$\hat{y}_{k l}=B_{l o}+B_{l l} x_{k t}+B_{l 2} X_{k 2}+\ldots+B_{l r} x_{k r} \quad(l=1,2, \ldots G)$

here,

$\mathrm{x}_{\mathrm{km}}=$ the mth dummy predictor score for $\mathrm{kth}$ individual. and

$B=$ the regression coefficients.

Partial derivatives of the ESS's with respect to the B coefficients are then calculated. These partials are then set to zero, yielding the $G$ normal equation sets $[1 ; 26]$.

In mathematical notation:

(2)

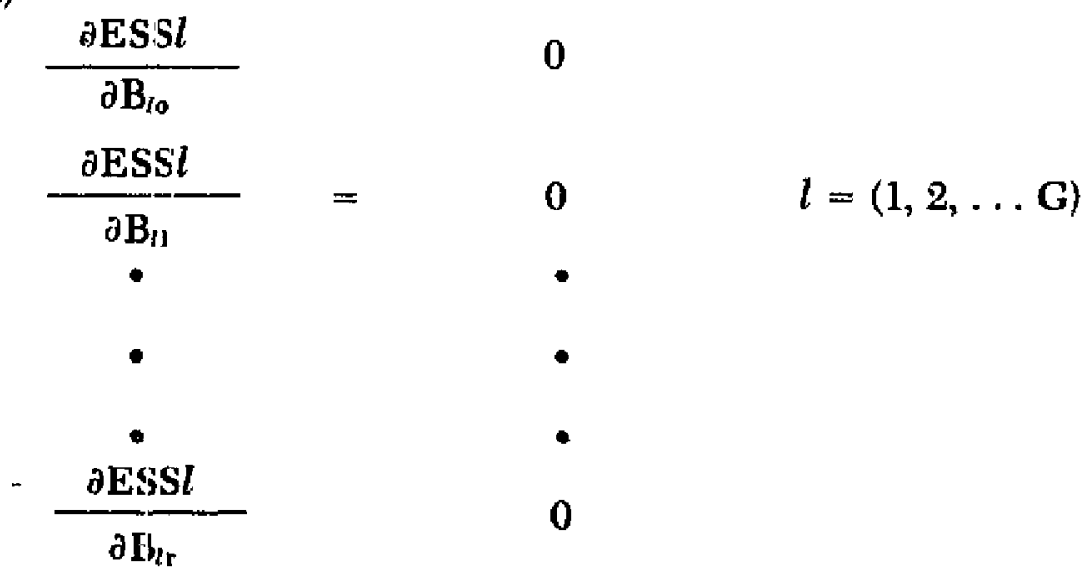

yelds the relevant normal equations. 
Solutions of these $G$ equations give the $B$ values for the predictive equations and a set of forecasts of indivitual scores $\left[\hat{y}_{k 1}, \hat{y}_{k 2}, \ldots\right.$ ,$\left.\hat{y}_{k G}\right]$. This solution ylelds values exprested as deviations from the one dummy prediction that was omitted irom each set. It is possible to present the predictive equations in a more easily understood form, while at the same time assigning value: to the previously omitted codes. MNA does this by transforming the results to a form where coefficients are expressed as deviations from the mean of the lth dependent variable [1:27-8]. Here,

(3) $\hat{y}_{l}=\bar{y}_{l}+A_{l l} x_{1}+A_{l 2} x_{2}+. A_{l:} x_{t} \quad(l=1,2, \ldots, G)$

where

$\bar{y}_{t}=$ the mean of the $l$ th dependent variable, and

$$
\begin{aligned}
& A_{l m}= \text { mth transformed dummy jererlictor regression } \\
& \text { coefficient for } l \text { th dummy dependent varable. }
\end{aligned}
$$

The $A_{I m}$ 's are expressed as ceviations from the grand means [ $\ddot{y}_{1}$, $\left.\bar{y}_{\mathrm{a}}, \ldots, \overline{\mathrm{y}}_{\mathrm{G}}\right]$. This system yields forecists that are identical to the previous system for all individuals and has coefficients attached to all categones of all independent variables. Coefficients are deviations from the grand mean $\bar{y}_{1}$, and not from the arbitrarily omitted category of each nominal independent variable as they would be if the equation was not transformec..

\section{Statistics Generated by MNA}

MNA generates both bivariate and multivariate statistics. Two bivariate statsstics are produced to measure the strength of the relationship between the dependent varable and each predictor. The first is the oneway analysis of variance ta-squared statistic which is calculated for each dummy dependent variable and then summarized into a generalized eta-squared. Eta-squared measures the explamed variance of each code and the generalized eta-squared statistic measures the explained variance across all codes, i.e., the ratio of explained sums of squares to otal sums of squares.

A more useful bivariate statistic, the bivariate theta $\left(\theta_{y}\right)$, is a relatively new statistic formulated by Messenger $[6,7]$ to measure the strength of association with correct placement in the dependent variable code as the criterion. Theta is defined as the proportion of the sample correctly classed when using a prediction-to-the-modal category strategy in each frequency distribution of each category of 
the predictor variable. For example, Table 1 presents a set of data from the cross-tabulation of a 3 code dependent variable $Y$, with a 3 code independent variable $X_{1}$. The number in the cells ar: the number of people in the sarnple assigned to the cells. If we knew nothing about the effect of $X_{i}$ on $Y$, our bust prediction con.erning $Y$ would be $\mathrm{Y}_{2}$, the modal category. That is, $\theta_{y}=400 / 10 \mathrm{C} 0=.40$ and we will have correctly classified subjects 40 percent of the time. Knowledge of $\mathrm{X}_{1}$ allows for improved classifications. specifically, if we know the subject is in $X_{i}$, the best guess is $Y_{1}, f . c$. Then,

$$
\begin{aligned}
\theta_{Y} / X_{1} & =(300+300+200) / 1000 \\
& =.80
\end{aligned}
$$

and we have correctly classified 80 percent of the subjects. ${ }^{2}$

Table 1. An Illustration of Bjvariate Theta

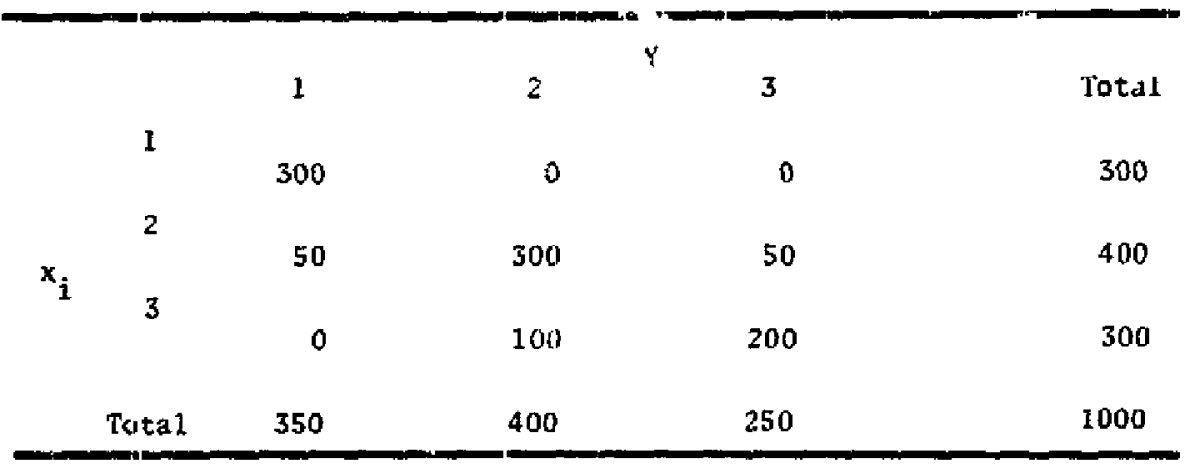

The multivariate statistics generated by MNA parallel the bivariate statistics described above. These are the generalized multiple $\mathbf{R}^{\prime \prime}$ and the multivariate theta statistic. The latter statistic is defined as the proportion correctly classed using a decision rule of predicting each individual a's being in that dependent variable category having the maximum forecast value for that individual and written as:

$$
\theta_{\mathrm{Y}} / \mathrm{X}_{1}, \mathrm{X}_{2}, \ldots, \mathrm{X}_{\mathrm{n}} \text {, or } \theta_{\mathrm{M}}
$$

It is the probability of placing a subject in the correct nominal category of the dependent variable, $Y$, given knowledge of the code values of the independent variables, $X_{1}, X_{2}, \ldots, X_{n}$, when using a prediction to the modal category strategy. It should be noted that multiviriate theta (or bivariate theta in the case of only one predictor variable) could be applied to the classification matrix generated by discriminant analysis. This matrix is identical in concept to the predicled versus actual category comparison undertaken by MNA. 
The MNA technique is a series of parallel MCA runs using each of the dummy variables in turn as the dependent variable. For each of the dependent variable codes, a preclicted probability $\left(\theta_{m}\right)$ of each subject being in that category is calculated. Each subject is predicted to fall in the dependent variable calegory for which he has the highest calculated probability. A comparison is made between the category each subject is predicted to be in and the category he is actually in, and the proportion correctl $v$ classified is then calculated.

\section{Relation to Other Techniques}

In their classification schemes for multivanate data analysis methods, Sheth [11] and Kinne ar and '] aylor [5] noted the absence of any technique to easily accrmpish a regression type analysis with all nominal variables. However, propedures other than MNA do exist. First, one could dichotomize the dependent varable, code it $0-1$ and do an analysis with MCA or dummy variable multiple regression. As noted previously, sucl a dependent variable gives inefficient estimators but can be cornected in this instance with a much more complex generalized least squares procedure. This whole option is limited to a dichotornous dependent variable.

A second option is available if the sependent variable has two or more categories. Discriminant analysis may be used with dummy independent varıables. This procedure and MNA yield identical predictuve rcsults. However, the results of a dummy variable discriminant analysis are very difficult to interpret. The coefficients of a discrumunane analysis are a new set of "tatistically derived predictors that are different from the predictors ;nput by the researcher [2.474]. From a conceptual, and interprelative point of view these coefficients are extremely hard to explain. MNA has the advantage of providing coefficients showing the effects of the original predictors (see [2:12] for details). MNA also off(rs a much easier input procedure. The user of dummy variable discriminant analysis must create his own dummy variables which MNA does automatically. In dummy variable discriminant analysis some independent variable could be left continuous with the resulting retention of metri: 11iformation. However, if nonlinear relationships exist between this variable and the dependent variable, the user must search for the proper trai sformation. MNA finds tlis nonlmearity automatically. Cther less well known techniques are also possibilities. They are not discussed here, but are compared to MNA by And'ews and Messenger [1:36-50] 


\section{An illustration ${ }^{3}$}

An example should help illustrate the type of analysis MNA can do for marketers. Suppose one is irterested in studying the characteristics of consumers who purchase particular types of brands in the detergent market. On the basis of cluster analysis of time series purchase data and of attitude data, five consumer typologies for the detergent market were developed. These are: (1) nonphosphate brand users (2) major brand users (3) private brand users (4) cents off brand users (5) bonus brand users (towels inside, etc.). These five categories of buyers are the dependent variable in our MNA analysis. The management of this company found this type of scherne as a useful way to classify their market They were prepared to de velop strategies against these typologies and wanted to know what consumer characteristics were related to each segment. The company had five independent variables of interest, all of which had been categorized. These variables are: (1) occupation of head of household (2) stage of life cycle (3) level of self confidence of head of household (4) family income, and (5) education. We note that occupation is a truly nominal variable, whereas life cycle, self confidence, education are probably ordinal and income could be treated as interval if left uncategorized. The point of using MNA with this data is that the nominal variable can be used and possible nonmonotonisity or nonlmearity in the other variables can be found s utomatically, without a troublesome and complex search for the best transformations. The data used in th: study were collected by means of a diary panel located in ten cities in the United States.

Table 2 present's the MNA results for the detergent user types as dependent variable and the available predictors $(N=1970)$. The first finding to note is the overall percentage distribution of respendents over the five categories of the dependent variable. We note that 10.4 percent were classified as no: phosphate brand users, 26.4 percent as major brand users, etc. The modal category was major brand users yieldiing $\theta_{y}$ equal to 264 . If we knew nothing about the characteristics of the respondents, we could predict the modal category and be right 26.4 percent of the time. The independent variables, $X_{1}$, $\mathrm{X}_{2}, \ldots, \mathrm{X}_{\mathrm{p}}$ serve to increase our ability to predict above this base levell.

The strength of relationship between the set of independent variables and the deperdent variable can be correlated in three ways. First, the generalized $\mathrm{R}^{2}$ equals .16, which indicates that approximately 16 percent of the variance in the dependent variable is explained. Second, we zan examine the category specific $R^{2}$ s. This 


\section{Table 2: MNA Results}

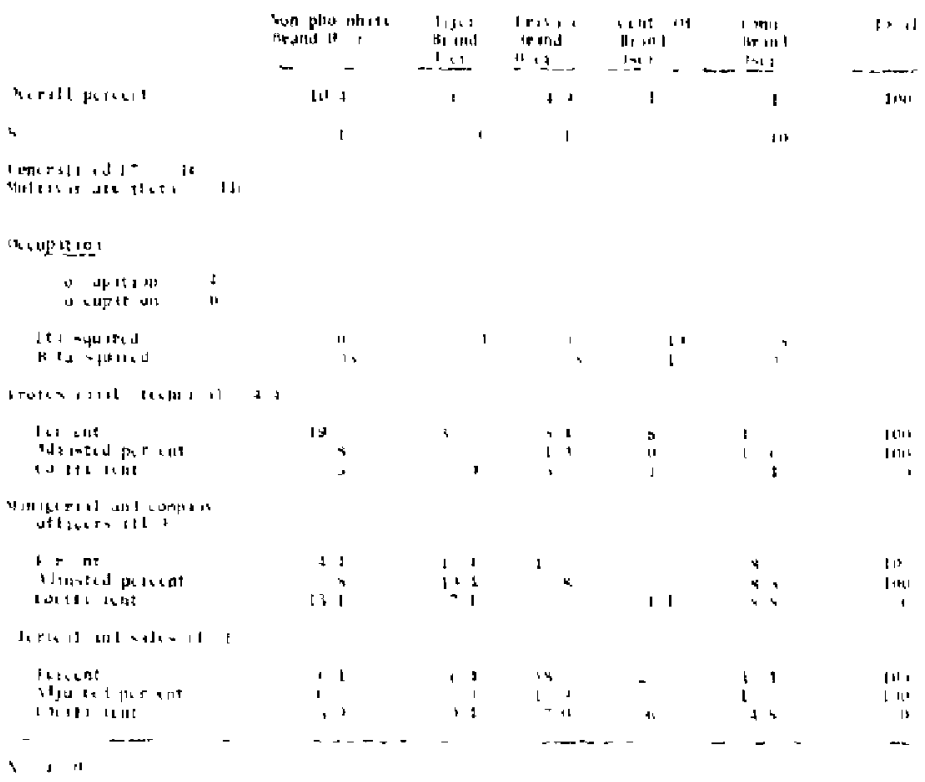

\section{Table 2: MNA Results Continued}

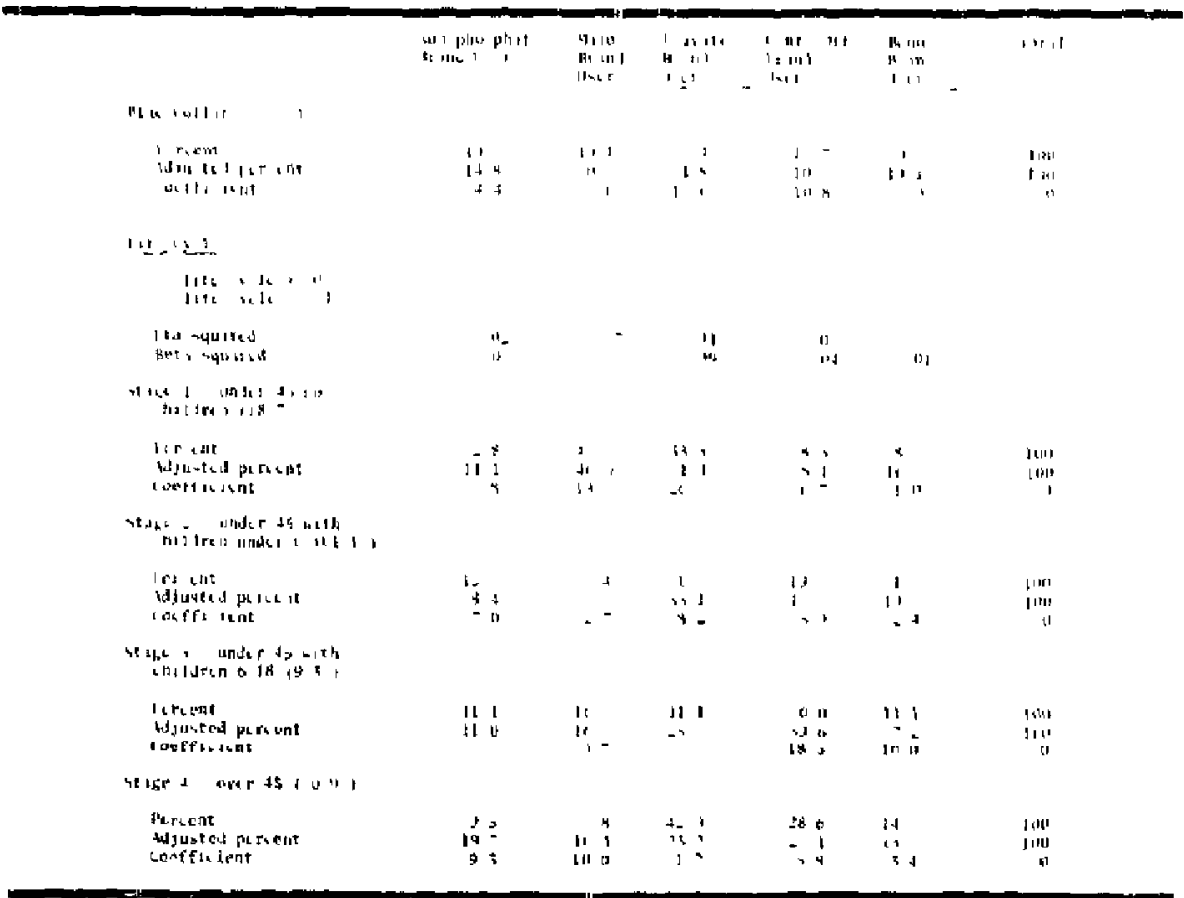




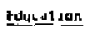

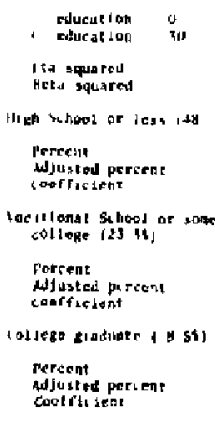

\begin{tabular}{|c|c|c|c|c|c|}
\hline 4 & ומו & H1 & a) & I & \\
\hline 5 & $\begin{array}{r}-1: \\
18 \\
18\end{array}$ & ${ }^{2} \cdot$ & $\begin{array}{l}14 \\
* 5\end{array}$ & I $^{119}$ & $\begin{array}{r}\text { Lutr } \\
\text { Iur| } \\
0\end{array}$ \\
\hline $\begin{array}{ll}5 \\
E \\
0\end{array}$ & +4 & נi & $\begin{array}{r}289 \\
0\end{array}$ & $\begin{array}{l}174 \\
178 \\
12\end{array}$ & $\begin{array}{r}2019 \\
\text { the } \\
0\end{array}$ \\
\hline $\begin{array}{ll}0 & 0 \\
3 & 1 \\
3 . & 1\end{array}$ & $\begin{array}{ll}\text { to } & 4 \\
5 & 1\end{array}$ & $\begin{array}{l}130 \\
-50\end{array}$ & $\begin{array}{l}9 \\
0 \\
6 \\
15\end{array}$ & 10 & $\underbrace{100}_{000}$ \\
\hline
\end{tabular}


examination indicates that the cents off bre-id user category was best predicted by the independent variable $\left(R^{2}=.22\right)$ and that the bonus brand user category was the lea it well predicted $\left(\mathrm{R}^{2}=.10\right)$.

Another way to examine the overall relationship between the dependent and independent variables is to note the multivariate theta value. This value is the percentage of respondents that could be correctly classified with know iedge of the independent variables. Multivariate theta, $\theta_{\mathrm{y}} / \mathrm{X}_{1}, \mathrm{X}_{2}, \ldots, \mathrm{X}_{\mathrm{p}}$, equals .440 . By comparing this value to $\theta_{y}, .264$, we note that these independent variables allow us to increase our correct prediction level by 17.6 percentage points $(44.0-26.4))^{4}$

MNA also produces a numbsr of predictor specific calculations and statistics. The generalized ta-squared and the bivariate theta are vitilized to indicate the strer gth of the bivariate association between an independent variable: and the dependent vanable. For example, for occupation, $\eta^{2}$ is .04 and $\theta$ is .36 , indicating that occupation explains .04 percent of the vanance and correctly classifies 36 percent of the sample. MNA also gives category-specific etasquareds and beta-squareds for each predictor. The latter statistic is an approximation of the ability of a predictor to explain variance of each category of the dependent variable while holding constint all other predictor variables.

The details of how each category of an independent variable is associated with each category of the dependent variable are $\#$ lso avallable. MNA produces thre,: sets of figures for each category of each independent variable to ,how these relationships. The "percent" figures give the bivariate percentage distribution of respondents across the categories of the de pendent variable By comparing rows of percents we can see, for example, that professional and technical respondents are moje likely to use nonphosphate detergents than the other occupatior al categones ( 19.2 percent ver sus 4.4 for the managerial category, 6.] for the clerical and sales and 10.3 for the blue collar category). In a similar fashion we note that blue collar respondents are more likely to purchase both bonas brands and pnvate brands than other occupational classifications. Other inde* pendent variable categories cin be examined in the same way.

The "coefficient" figures give the effect of being a specific category of a predictor variable on the likelihood of a respondent being in each category of the dependent variable. Those coefficients are the heart of the multivariate analysis. An individual's predicted probability of being in a specilic category of the dependent variable 
is equal to "overall percent" for that category plus the coefficients across all predictor categories relevant to that respondent and that dependent variable category. The coefficients can be interpreted as the amount of increase or decrease in likelihood of dependent variable category membership after holding constant all other predictor variables. The "adjusted percent" figures are formed by adding the coefficient for that eategory of the dependent variable to the relevant "overall percent." 'The result is the percentage distribution of respondents across categories of the dependent vanable after allowance has been made for the effects of other predictors.

Examination of the results presented in Table 2 allows the marketer to form a portrait of those using partıcular types of detergent brands. For example, major buand users can be described as lending to have the following characteristics:

1. Employed in professional and technical orcupations Adjusted

Percent Percent

2. Under 45 with no children

3. Medium level of self confidence

4. Eamings of from $\$ 12,000$ to

$\begin{array}{rr}\text { Percent } & \begin{array}{r}\text { Adjust } \\ \text { Perce }\end{array} \\ 36.2 & 32.3 \\ 47.2 & 46.0 \\ & \\ 34.6 & 31.5 \\ & \\ 36.1 & 37.2 \\ 36.4 & 32.5\end{array}$

5. College graduate

It is possible to select a specific consumer profile and determine the likelihood that people with those characteristics are major brand users. Spectficall $r$, those having the above characteristics have a predicted probability of using a major detergent brand of .714, up from the base probability of .264 . This predicted probability is calculated by adding the coefficients in these categories to the overall percent using major brands. ${ }^{5}$ Similar descrnphons and calculation can be undertaken for other detergent user types.

Table 3 presents a classification matrix that compares actual classification on the dependent variable with the categories predicted by MNA. The diagonal elements indicate the proportion correctly classified for each dependent variable category. Table 3 also shows the nature of the misclassifications that did occur. We note that for major brand users 60.8 percent were correctly predicted as being major brand users, none were incorrectly predicted as nonphosphate bland users, 15.7 were incorrectly predicted to be private brand users, etc. The users of misclassifications for the other 
Table 3: Classification Matrix

\begin{tabular}{|c|c|c|c|c|c|}
\hline \multirow[t]{2}{*}{ Actual } & \multicolumn{5}{|c|}{ Predicted } \\
\hline & $\begin{array}{l}\text { Nen-phosphate } \\
\text { Brand User }\end{array}$ & $\begin{array}{l}\text { Major } \\
\text { Brand } \\
\text { User }\end{array}$ & $\begin{array}{l}\text { Private } \\
\text { Brand } \\
\text { User }\end{array}$ & $\begin{array}{l}\text { Cents off } \\
\text { Brand } \\
\text { User }\end{array}$ & $\begin{array}{l}\text { Bonus } \\
\text { Brand } \\
\text { User }\end{array}$ \\
\hline $\begin{array}{l}\text { Non-phosphate } \\
\text { brand user } \\
(\mathrm{N}=200)\end{array}$ & $20.0 \%$ & $350^{\circ}$ & 1000 & $200 \%$ & $15.0^{\circ}$ \\
\hline $\begin{array}{l}\text { Major brand } \\
\text { user } \\
(N=510)\end{array}$ & 0.0 & $60 \mathrm{~s}$ & 15,7 & 196 & 39 \\
\hline $\begin{array}{l}\text { Private brand } \\
\text { user } \\
(\mathrm{N}=480)\end{array}$ & 21 & 229 & 458 & 146 & 146 \\
\hline $\begin{array}{l}\text { Cents off } \\
\text { brand user } \\
(N=410)\end{array}$ & 00 & 220 & 195 & 488 & 98 \\
\hline $\begin{array}{l}\text { Bonus brand } \\
\text { user } \\
(N=330)\end{array}$ & 0.0 & 242 & 303 & 212 & 24.2 \\
\hline
\end{tabular}

detergent segments are als $i$ avallabie from Table 3 . The nature of the misclassifications that do occur gives the marketer a view of the extent to which segments overlap in terms of characteristics. Table 3 also allows the user to dete rnine the degree to which he is able to predict membership in particular segments. In this illustration, major brand users were the most successfully predicted, and nonphosphate users were the least successfully predicted.

\section{Potential Uses}

Differences found in the socioeconomic profile of each consumer typology could be used to help select appropriate media vehicles, design packages, select relevant actors for commercials, etc. In additon to MNA's usefulness in segmentation analysis and planning, it has great potential for som! ' of the purposes described in the following examples.

1. The sales force for a company could be evaluated, with each salesman being put in a performance category such as well above average, slightly above average, average, etc. MNA could then be used to examine a numlser of determinants in an effort to describe which variables are assoctated with each of the categories of salesman performancel. 
2. MNA could be used to identify and describe geographical terntories which ofter the greatest profit opportunities The counpany', market areas could be defined into certain categories, sumilar to those described in the sales force analysis example above, with MNA then used to identify the variables most important in describing the better territories.

3. MNA could be utilized to assist in medra planning, A number of media choxces could be analyzed using a vanety of demographic, psychographic, and product usage vanables. The result would be useful in comparing various media audiences and a company's target market.

4. The new product development process is another area where MNA has potential ust fulness. After several different prototypes had been developed, the importance of a variety of independent variatles could be examined utllizang MNA to determine which variakles were associated with preference for each of the prototype's. This analysis would indicate which segments of the market would offer the highest potential for each of the prototypes.

5. Demographic and personal characienstics associated with users of different brands could be analyzed using MN4. This would enable the marketer to examine user profiles for eash of a number of competitive brands. Similarly, users of a product could be divided into several usage categories, varying from very heavy user to very light user, with MNA being used to determine the profiles of those in each category.

6. The analysis of credit risks is another potental area for the use of MNA Multiple discriminant analysis is often $t i t \mathrm{~d}$ to evaluate credit risks now, but MNA offers the additional advariage of being able to include nominal level independent variabus in the analygis, thus offering the potential for better descrptior. of the various risks categories.

\section{Summary and Conclusions}

Since MNA is capable of handling nominal variables as both predictors and sraterion variables, it is a useful technique for marketing research irs. Now categorical dependent variables such as brand choice, consumer typologies, switching patterns, media choices, etc., can be handled un a regression type arialysis with categorical indepenclent variables, such as region of country, occupation, sex, race, exposure to marketing programs, stage of life cycle, etc. The potential uses of the MNA technique in marketing seem extensıve. 


\section{Footnotes}

The authors wish to thank the JBR reviewers and Editor for therr most belpful comnitnts

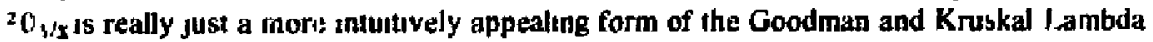
statisuc. $\lambda_{1}$. which is definerl as the proportion of reduction in error given predictor $X_{i}$ is codes

$$
\begin{aligned}
\lambda_{1} & =\left(\theta_{\mathrm{V}} / \mathbf{Y}_{1}-\theta_{1}\right) /\left(1-\theta_{y}\right) \\
& =(80-40) /(1-40) \\
& =67
\end{aligned}
$$

In this example error has been reduced from 6 to 2 by the knowledge of the association between $X_{4}$ and $Y$ It can be seen that it represents a 67 reduction tn error as calculated by $\lambda$ above.

The data used un this tlustration are the disguised results of a real study The errence of the type of design used anil nature of results remans the same

We note here that $\lambda=\frac{441-264}{1-264}=24$

$\begin{array}{lr}\text { s Base percent } & \\ \text { Catrgory Effects } & \\ \text { Professional, technical } & 59 \\ \text { Under 45, no children } & 196 \\ \text { Medum self confidence } & 51 \\ \$ 12,000 \text { to } \$ 14,999 & 108 \\ \text { College graduate } & 6 \text { I }\end{array}$

\section{$\underline{475}$}

$\underline{\underline{73.9}}$

Base probability $=264$

Fredicted probabilaty for respondents having these churactenstuc $=739$

Increase in probability dile to knowledge of predictors $=739-264-475$

\section{Reference}

1 Andrews, FM and Mesuenger, RC Multuanate Nomanal Scale Analysis Ann Arbor, Michigan Instrtute for Sor.al Research, Lniversity of Michigan, 1973

2 Audrews, F M , Morgan, J N , and Messenger, $7 \mathrm{C}$ "Comments on Reviews by Jagdish $\mathrm{N}$ Sheth of MNA and TFAID." Joumal of Marketing Research 11 (November 1974) 473475

3 Andrews, F M and Sinquist, I A The Multiple Classefication Analysis Program. Ann Arbor, Michigan. Insti ute for Social Research, University of Michigan, 1967

4 Frank, R E, Massy, U F., and Wnd, Y Market Segmentatıon Englewood Cliff, New Je rsey Prenice-Hall, inc, 1972, 139-69

5 Kinnear, TC and Taylor, I A. "Multivanate Methods in Marketung Research A Firther Attempt at Classificatu on " Jourmal of Marketıng 34 (Ottober 1971). 56-9

6 Messenger, A.C Thet is User's Guide Unpublished manuscript, Ann Arbou, Michugan. Instutute for Social Re'search, University of Michigan, 1971

7. Messenger, R.C and Mandell, L M "Modal Search Technıque for Predichve Nomanal Scale Multivanaie An viysis." Joumal of the Ameracan Statistical Assoctation 67 (December 1972) 
8 Newman, J.W and Stakin, $\mathbf{R}$ "Multwarrate Auralysts of Differences in Buyer Decision Tume,' Jatrmal of Marketing Research 8 (May 1971). 192-8

9. Newman, JW "Prepurchase Information Seeking for New Cars and Major Household Appliances "Journal of Marketing Research 9 (August 1972) 249-57

10 Peters, W H. "Usıng MCA to Segment New-Car Markets" Joumal of Marketing Hesearch 7 (August 1970) 360-3

11 Sheth, IN "The M dltrariate Revolution in Mezketning Research "Joumal of Marketzing 34 (January 1971) 13-9

12 Sheth, J.N "Bonk Feview of Multwariate Nominal ScaleAnalysis and THALD A Sequential A nalyses Program for The Analysis of Nom-nal Scale Dependent Lariable "Joumal of Marketing kesearch 11 (May 1974) 228-232

13. Suts, DB. "Use of Dummy Vanables in Regression Equation " Joumal of Amercan Statistreal Asrociation $\{2$ (1957). 548-51 